\title{
Percutaneous coronary intervention versus bypass grafting in left main coronary artery disease
}

\author{
Stine Munkholm-Larsen ${ }^{1}$, Tristan D. Yan $^{1,2,3}$ \\ ${ }^{1}$ Collaborative Research Group, Macquarie University, Sydney, Australia; ${ }^{2}$ University of Sydney, Sydney Adventist Hospital, Wahroonga, NSW, \\ Australia; ${ }^{3}$ University of Sydney, Central Clinical School, Royal Prince Alfred Hospital, Sydney, Australia \\ Correspondence to: Dr. Stine Munkholm-Larsen, MD. Collaborative Research Group, Macquarie University, Sydney, Australia. \\ Email: stinemunkholm@gmail.com.
}

Submitted Sep 24, 2016. Accepted for publication Oct 05, 2016.

doi: $10.21037 /$ jtd.2016.10.50

View this article at: http://dx.doi.org/10.21037/jtd.2016.10.50

Without revascularization, patients with left main coronary artery disease (LMCAD) have a poor prognosis (1). There is a clear survival benefit from revascularization over medical management (1). Percutaneous coronary intervention (PCI) has been traditionally deferred in preference for coronary artery bypass grafting (CABG), due to the anatomic complexity (2). However, with the evolution of drug-eluting stents (DES), there has been a reduction in restenosis rates and mortality, repeat revascularization and major adverse cardiac and cerebrovascular events (MACCE) compared with bare metal stents (3). There has been a renewed interest in expanding the indication for PCI in patients with LMCAD (3). Despite this heightened interest in the comparative outcomes of DES versus CABG for patients with $\mathrm{LMCAD}$, the choice for the optimal revascularization technique remains controversial.

A recent meta-analysis by $\mathrm{Li}$ and co-workers indicated that DES was associated with lower peri-procedural risks than $\mathrm{CABG}$, but was inferior to CABG in terms of repeated revascularization in patients with LMCAD at 5 years (4). There was no difference in death, myocardial infarction, cerebrovascular events or revascularization between randomized controlled trials and observational groups (4). It is important to point out that LMCAD includes a wide spectrum of anatomic features and it may be associated with concurrent multi-vessel disease. Previous studies have shown that $70 \%$ to $90 \%$ of patients with LMCAD will present with multi-vessel coronary artery disease $(5,6)$. A recent meta-analysis by Cao et al. demonstrated that patients with LMCAD and concomitant multi-vessel disease may be underrepresented in the comparative studies (7). In the real world, patients are more likely to undergo CABG, if they are found to have LMCAD in combination with multi-vessel disease (7).

Studies evaluating more than 5 -year outcomes of PCI versus CABG in patients with LMCAD are limited. Subgroup analysis of LMCAD patients in the SYNTAX randomized trial recently reported comparable 5-year cardiovascular outcomes for PCI and CABG (8). The randomized control trial is the gold standard for comparing treatments, but generally enrolls selective patients without high-risk profiles. Perhaps more importantly, it should be highlighted that only a minor proportion of patients assessed for eligibility were eventually randomized in the SYNTAX trial. Of the patients who were excluded from randomization, 198 patients who underwent DES and 1,077 patients who underwent CABG were included in a separate nested registry, which found higher incidences of MACCE, mortality, myocardial infarction, and repeat revascularization for patients who were treated by DES at 12 months. The main reason for registry allocation to CABG (70.9\%) was the complexity of anatomy, whereas the main reason for PCI allocation was increased comorbidity (70.7\%). Likewise, a randomized controlled trial by Boudriot and colleagues compared 100 patients who underwent DES with 101 patients who underwent CABG (9). The authors reported similar combined incidences of cardiac death, myocardial infarction, and repeat revascularization at 12 months $(19.0 \%$ vs. $13.9 \%, \mathrm{P}=0.19$ for non-inferiority). However, of the 229 patients with LMCAD who were considered ineligible for randomization, a significantly lower incidence of 
MACCE was reported for CABG compared with DES and conservative therapy (17.8\% vs. $27.5 \%$ vs. $43 \%)$ ). Although reasons for exclusion from randomization differ between trials, it should be emphasized that results derived from patients selected for randomization in these tertiary referral centers do not necessarily represent the target population of patients diagnosed with LMCAD, especially those with more complex disease.

The 5-year follow-up results from the SYNTAX randomized trial and the 5-year outcome from CREDOKyoto PCI/CABG Registry Cohort-2-confirmed the utility of the SYNTAX score for risk stratification and selection of mode of revascularization procedure, supporting the current updated clinical guidelines for LMCAD (8,10-13). In LMCAD patients with relatively less anatomical complexity, represented by a low or intermediate SYNTAX score, PCI using DES is a reasonable alternative to $\mathrm{CABG}$ in real-world clinical practice. However, CABG still remains the preferable treatment for LMCAD patients, especially those with high anatomical complexity (i.e., high SYNTAX score or complex multi-vessel disease).

\section{Acknowledgements}

None.

\section{Footnote}

Conflicts of Interest: The authors have no conflicts of interest to declare.

\section{References}

1. Chaitman BR, Fisher LD, Bourassa MG, et al. Effect of coronary bypass surgery on survival patterns in subsets of patients with left main coronary artery disease. Report of the Collaborative Study in Coronary Artery Surgery (CASS). Am J Cardiol 1981;48:765-77.

2. Ragosta M, Dee S, Sarembock IJ, et al. Prevalence of unfavorable angiographic characteristics for percutaneous intervention in patients with unprotected left main coronary artery disease. Catheter Cardiovasc Interv 2006;68:357-62.

3. Stettler C, Wandel S, Allemann S, et al. Outcomes associated with drug-eluting and bare-metal stents: a collaborative network meta-analysis. Lancet 2007;370:937-48
4. Li Q, Zhang Z, Yin RX. Drug-eluting stents or coronary artery bypass grafting for unprotected left main coronary artery disease: a meta-analysis of four randomized trials and seventeen observational studies. Trials 2013;14:133.

5. Serruys PW, Morice MC, Kappetein AP, et al.

Percutaneous coronary intervention versus coronary-artery bypass grafting for severe coronary artery disease. $\mathrm{N}$ Engl J Med 2009;360:961-72.

6. Taggart DP, Kaul S, Boden WE, et al. Revascularization for unprotected left main stem coronary artery stenosis stenting or surgery. J Am Coll Cardiol 2008;51:885-92.

7. Cao C, Manganas C, Bannon P, et al. Drug-eluting stents versus coronary artery bypass graft surgery in left main coronary artery disease: a meta-analysis of early outcomes from randomized and nonrandomized studies. J Thorac Cardiovasc Surg 2013;145:738-47.

8. Morice MC, Serruys PW, Kappetein AP, et al. Five-year outcomes in patients with left main disease treated with either percutaneous coronary intervention or coronary artery bypass grafting in the synergy between percutaneous coronary intervention with taxus and cardiac surgery trial. Circulation 2014;129:2388-94.

9. Boudriot E, Thiele H, Walther T, et al. Randomized comparison of percutaneous coronary intervention with sirolimus-eluting stents versus coronary artery bypass grafting in unprotected left main stem stenosis. J Am Coll Cardiol 2011;57:538-45.

10. Shiomi H, Morimoto T, Furukawa Y, et al. Comparison of Percutaneous Coronary Intervention With Coronary Artery Bypass Grafting in Unprotected Left Main Coronary Artery Disease - 5-Year Outcome From CREDO-Kyoto PCI/CABG Registry Cohort-2 - . Circ J 2015;79:1282-9.

11. Levine GN, Bates ER, Blankenship JC, et al. 2011 ACCF/AHA/SCAI Guideline for Percutaneous Coronary Intervention: a report of the American College of Cardiology Foundation/American Heart Association Task Force on Practice Guidelines and the Society for Cardiovascular Angiography and Interventions. Circulation 2011;124:e574-651.

12. Task Force on Myocardial Revascularization of the European Society of Cardiology (ESC) and the European Association for Cardio-Thoracic Surgery (EACTS)1; European Association for Percutaneous Cardiovascular Interventions (EAPCI), Wijns W, et al. Guidelines on myocardial revascularization. Eur Heart J 2010;31:2501-55.

13. Authors/Task Force members, Windecker S, Kolh P, 
et al. 2014 ESC/EACTS Guidelines on myocardial revascularization: The Task Force on Myocardial Revascularization of the European Society of Cardiology (ESC) and the European Association for Cardio-
Thoracic Surgery (EACTS)Developed with the special contribution of the European Association of Percutaneous Cardiovascular Interventions (EAPCI). Eur Heart J 2014;35:2541-619.
Cite this article as: Munkholm-Larsen S, Yan TD. Percutaneous coronary intervention versus bypass grafting in left main coronary artery disease. J Thorac Dis 2016;8(10):26772679. doi: $10.21037 /$ jtd.2016.10.50 